\title{
Managers social support: Facilitators and hindrances for seeking support at work
}

Daniel Lundqvist, Anna Fogelberg Eriksson and Kerstin Ekberg

The self-archived postprint version of this journal article is available at Linköping University Institutional Repository (DiVA):

http://urn.kb.se/resolve?urn=urn:nbn:se:liu:diva-147595

N.B.: When citing this work, cite the original publication.

Lundqvist, D., Fogelberg Eriksson, A., Ekberg, K., (2018), Managers social support: Facilitators and hindrances for seeking support at work, Work, 59(3), 351-365. https://doi.org/10.3233/WOR-18269o

Original publication available at:

https://doi.org/10.3233/WOR-182690

Copyright: IOS Press

http://www.iospress.nl/ 
Managers’ Social Support: Facilitators and Hindrances for Seeking Support at Work

Daniel Lundqvist ${ }^{\mathrm{a}, \mathrm{b}, \mathrm{c} *}$, Anna Fogelberg Eriksson ${ }^{\mathrm{a}, \mathrm{b}}$ and Kerstin Ekberg ${ }^{\mathrm{a}, \mathrm{c}}$

${ }^{\text {a } H E L I X ~ V I N N ~ E x c e l l e n c e ~ C e n t r e, ~ L i n k o ̈ p i n g ~ U n i v e r s i t y, ~} 58183$ Linköping, Sweden

${ }^{\mathrm{b}}$ Unit of Education and Sociology, Department of Behavioural Sciences and Learning,

Linköping University, 58183 Linköping, Sweden

${ }^{\mathrm{c}}$ National Centre for Work and Rehabilitation, Department of Medical and Health Sciences, Linköping University, 58183 Linköping, Sweden

*Corresponding author: Daniel Lundqvist, Department of Behavioural Sciences and Learning, Linköping University, 58183 Linköping, Sweden. E-mail: daniel.lundqvist@liu.se. Tel.: +46 13284494. 


\section{Abstract}

BACKGROUND: Previous research has shown that social support is important for health and performance at work, but there is a lack of research regarding managers' social support at work, and if it needs to be improved.

OBJECTIVE: To investigate managers’ perception of work-related social support, and facilitators and hindrances that influence their seeking of social support at work.

METHODS: Semi-structured interviews with sixty-two managers in two Swedish organizations.

RESULTS: Work-related support, which strengthened their managerial image of being competent, was sought from sources within the workplace. Sensitive and personal support, where there was a risk of jeopardizing their image of being competent, was sought from sources outside the workplace. Access to arenas for support (location of the workplace, meetings, and vocational courses) and the managerial role could facilitate their supportseeking, but could also act as hindrances. Because attending different arenas for support were demanding, they refrained from seeking support if the demands were perceived as too high. CONCLUSIONS: Different supportive sources are distinguished based on what supportive function they have and in which arenas they are found, in order to preserve the confidence of the closest organization and to maintain the image of being a competent and performing manager.

Keywords: Image, Health, Leadership, Work conditions 


\section{Introduction}

While a considerable amount of research has been devoted to showing the importance of different types of social support for health and performance at work, much less research has focused on who provides the support and circumstances that may facilitate or hinder the seeking of support [e.g. 1-6]. The lack of research regarding these issues are particularly evident in managers. The overall purpose of this study is therefore to increase knowledge about managers' perception of work-related social support and facilitators and hindrances that helps respectively inhibits managers from seeking social support at work.

\subsection{Literature review}

Resources received from people in social relationships that directly or indirectly help an individual regarding a certain problem are defined in this paper as social support. This definition is consistent with previous definitions [6-9] which have theoretical roots in social exchange theory [10-11]. Social support is also regarded as a broader concept for several qualitatively different types of resources. This is consistent with House [7], who defined social support "as an interpersonal transaction involving one or more of the following: (1) emotional concern (liking, love, empathy), (2) instrumental aid (goods or services), (3) information (about the environment), or (4) appraisal (information relevant to selfevaluation)” (p. 39).

The term social support originates from health research [3-4,7], and has mostly been studied using health-related outcomes. Studies of managers' work situations often show that they have a large workload [12-16], their work tasks are fragmented [12-13,15-18] and they are often subjected to conflicts between upper management and subordinates [14,19-20], which they are dependent on for the accomplishment of their work [15-16,21]. Availability of social support has been suggested to mitigate the resulting strain of such work situations. In managers, social support has been associated with decreased stress and strain [22-24], fewer 
symptoms of burnout [25], higher self-rated health [26], lower physiological stress [27], and less sickness absence [28]. Recent studies have also shown that managers' social support is positively related to other work-related issues besides stress and health, such as leadership development [29-31], workplace learning [33], work-life balance [22,34] and performance [35-36]. However, several studies suggest that managers perceive less support in their workplace than non-managers [37-40].

When studying social support, it is important to distinguish between the type of support, or resources, being exchanged; who provides the support; and why the support is given or what problems the support addresses. This was pointed out by House [7] when he said that in order to fully understand the concept of social support we need to know "who gives what to whom regarding which problems” (p. 22). Different types of social support may have different effects. Lingard and Francis [41] found that emotional support had a direct effect on managers' burnout, and instrumental support had a buffering effect between work/family conflict and burnout. In addition, different sources of support may differ in importance. Love and Edwards [42] showed that supportive sources outside the workplace were better predictors of managers' health and job satisfaction than supportive sources within the workplace. These kinds of results have given rise to the optimal matching hypothesis [4,43], which states that, for social support to be effective, the right type of support must be provided by the right source for a certain problem. How contextual factors influence the exchange of social support have however not received much attention [1-6]. One reason might be the considerable focus on the effects of, rather than circumstances around, social support [3-4].

The whole support chain, i.e. types of social support, sources of support, and the problems for which the support is provided, has rarely been studied in managers. An exception is Lindorff's [4] cross-sectional study, in which she showed that emotional support was more 
often provided by sources outside managers’ workplace, whereas instrumental and informational support were provided by sources in the domain in which the stress occurred.

Different aspects of work has further been investigated to explain where managers' seek support and whether this support is accessible to them [2-3]. The organizational work space, in terms of arrangement of the physical environment [44], and access to informal arenas for communication [23,45-46], as well as the degree of control over the job [5], may act as facilitators and influence how people make contact and establish relationships. Organizational practices, such as managers' access to executive education [31,46-48] and mentorship [48-50] have also been shown to facilitate the provision of social support to managers.

Hindrances at work that prevent managers from seeking or gaining support, has been much less researched. Aspects that has been described to facilitate support in managers may possibly be reversely conceived as hindrances, that is, lack of arenas for communication, low degree of control over the job etc. Previous research has found that managers thought it was hard to ask for support from people they worked with, particularly when it was concerned with feeling stressed and exhausted or having too much to do [45,51-52]. Maintaining an image of being a competent and able manager is important for being accepted as an authority, maintain the trust of the organization and for the managers to be able to carry out their work [53-59]. Managers’ perceived threats to their image have been shown to have consequences for their willingness to propose changes to top managers [60-62]. This perception may hence be relevant as a potential hindrance for their support-seeking.

Receiving social support may not always be a good thing; research has shown that it may also be associated with increased stress [4,6,26,63-64]. Two hypotheses have been formulated to explain such conflicting findings [6,65-67]. One hypothesis suggests that receiving support may create a sense of being in debt to the person who provided the support and being obligated to reciprocate (the inequity hypothesis). The other hypothesis suggests that 
receiving support harms a person’s self-esteem and lowers a person’s social status (the esteem threat hypothesis). Thus, these hypotheses imply that the perceived consequences of the support may hinder the managers from seeking support.

In summary, previous research has found that social support is important for managers, although they may not experience the same amount of work-related support as non-managers. More knowledge is therefore needed regarding what support managers have, from whom they get it, and why this is important. House’s support chain [7] is useful for gaining such knowledge. To be able to increase managers' social support at work, more knowledge is needed regarding facilitators and hindrances at work that helps respectively inhibits managers from seeking support.

Therefore, the research questions of this study are: 1) What characterizes managers' social support at work: what supportive sources do they have, what support does the sources provide, and why is this support important? 2) What do managers perceive facilitates or hinders their seeking of social support at work?

\section{Method}

\subsection{Research Setting and Data Collection}

This study is based on a qualitative approach consisting of interviews with managers. A qualitative approach was chosen for its potential contribution to the understanding of the complex phenomenon that is social support, and its facilitators and hindrances. Interviews were chosen to allow the managers to describe in their own words their perceptions and experiences, and their own thoughts and analyses of the subject could be captured and used [68].

Our material consists of 62 semi-structured interviews with male and female managers at three managerial levels in two organizations. Forty-two of the managers worked in a large 
Swedish industrial production company, and 20 managers worked in a medium-sized Swedish municipality (Table 1).

[Insert Table 1 about here]

The two organizations and the participating managers were selected to ensure variation in the material. The organizations were both situated in the same geographical region, and they each had about 2000 employees. In the private organization, $80 \%$ of the employees were men, whereas in the municipal organization $80 \%$ were women. The private organization acted in a competitive international market, specializing in products and services in materials handling and logistics. A few years earlier, the company was bought by a larger international enterprise and a new production system inspired by the Toyota Production System [69] was implemented. The municipal organization, on the other hand, was a regional part of the Swedish welfare system and a politically driven organization to secure citizens' basic rights and services in that region.

The participating managers were selected by the researchers based on the organizational scheme from each organization. Wherever possible, selections were made to include both men and women from all three managerial levels within each division of the organization. All selected managers agreed to participate after they had been informed about the purpose of the study, and told that the information provided would be treated confidentially and that participation was voluntary.

The managers were interviewed using a semi-structured interview guide [68] concerning their work, leadership, learning and career development, recruitment and health. Some of the questions specifically dealt with perceived social support from top management, other managers, and subordinates. Examples of interview questions posed to all participants were: 
"What people do you meet during a working day, and in what contexts do you meet? How do you get support from a) top management b) other managers c) subordinates? How does the organization help you deal with the expectations placed on you as a manager?”

All managers were interviewed face-to-face at their offices or at other suitable places during working hours within each organization. After receiving consent from each manager, all interviews, which lasted between one and two hours, were audio-taped and subsequently transcribed verbatim by a professional transcriber.

\subsection{Data Analysis}

The data analysis was performed in accordance with qualitative content analysis [70-72]. The analysis began by focusing on social support, and later on facilitators and hindrances for managers' social support.

The analysis was inspired by House’s [7] statement that researchers need to investigate the whole support chain. So as not to limit the richness of the material, we chose to let the types of support be generated from the managers’ descriptions, rather than use House’s predefined typologies. House's four typologies of support were used as comparisons later in the analysis.

In the first step, all transcriptions were read through several times to gain a general impression of the material. In the next step, the coding procedure began. All people or groups of people who were described as providing support or help to the manager were coded under

the label "source of support”. The particular type of support or help was coded under the label “type of support”. The manager's description of why he/she thought the particular type of support was important was coded under the label “importance of support”. Each individual manager described approximately 10-15 different sources of support in their interviews.

This process generated a matrix for each individual manager, in which the whole support chain was preserved (Who-What -Why). These individual matrixes were then combined into two matrixes, one for each organization. 
In the next step, the codes for each part of the support chain the managers had described were compared (e.g. types of support), and several descriptions with similar content were found. After returning to the managers' original statements, suitable codes were combined to reduce their number. These reduced numbers of codes were used to create descriptive categories of the sources of support, the types of support, and the importance of the support.

The contents of the descriptive categories in the two organizations were then compared with each other, i.e. the supportive sources mentioned in each organization were compared; the different types of support from each supportive source were compared, etc. This made it possible to see patterns of similarities and differences in each part of the support chain, but also the relationship between all three parts of the support chain for the two organizations. We also compared our generated categories with House's [7] four typologies to emphasize the similarities and differences between us. The tables in the results section show our categories and House's corresponding typologies.

The second focus of our analysis concerned facilitators and hindrances for managers' social support-seeking. We focused our reading on instances where managers talked about aspects that helped them seek support (coded as "facilitators") or aspects that made it more difficult to seek support (coded as "hindrances"). We also made notes on whether the managers referred to the type of support, the source of support or the importance of the support in their descriptions.

The analysis was conducted mainly by the first author. To ensure validity and reliability of the results, the codes and categories were continuously discussed with the co-authors until agreement was reached [73]. Quotes were later selected to illustrate the content of the descriptive categories.

\section{Results}


The results section is divided into two parts, the first of which concerns the support chain (Who-What-Why). The second part concerns facilitators and hindrances of social support. Only a few differences were found between the two organizations, which are noted below.

\subsection{The social support chain}

In the managers' descriptions of their work-related social support, seven different types of support were discernible (Table 2). These types were important as they helped in completing their work tasks, develop their leadership, or maintain their health and well-being, and were sought either from sources within or outside the managers’ workplaces.

\subsubsection{Information, discussion, ventilation}

When the managers described the support they obtained from supportive sources within the workplace, i.e. managerial colleagues, superior managers, or subordinates, the support was often concerned with receiving valuable information about the work they were doing and how the tasks were progressing. It also concerned discussing problems they encountered during their work and discussing how to change, improve or structure work tasks (Table 2).

\footnotetext{
There are certain questions that we sort of bandy around in our [division], certain things like "How would you deal with this” and that's good of course. I’m quite happy to bring things up. // You can have a good dialogue there. (Male first-line manager, private organization)
}

The support helped the managers to decide on what to prioritise in their work, but they also thought that it contributed to an image of them as being competent and able. If they were perceived as being highly informed, the decisions they made would be conceived as being more reasoned and would face less resistance. The managers also said that they felt stressed if they did not receive this information when they needed it, because they could not perform their work satisfactorily.

I mean, if I don't get clear information from upstairs I don’t feel that I'm a very good boss. // And for me it's important that I sort of know where we're going, and sometimes we don't know that. And that often leads to, 
what should I say, unclear information, and giving unclear information is the worst thing you can do as a manager. It's got to be clear information. (Female first-line manager, municipal organization)

When the managers needed to discuss their leadership, how to motivate and inspire subordinates and how to handle difficult personnel issues, or when they needed to ventilate and talk about the problems and stress they experienced, they turned to people outside the workplace, whom they did not work closely with. They mentioned sources outside their workplace such as mentors, managerial colleagues outside the organization, support functions within or outside the organization, or customers.

Get yourself contacts, someone that you feel comfortable talking rubbish with, get out there and vent some of your anger about what the situation's like, and I mean finding that person is really important (...) Get away from it all. // It's a question of finding those ventilation holes. (Male middle manager, private organization)

\subsubsection{Social belonging}

An additional type of support concerned social belonging in the workplace. Many described that they belonged to a community at work in which they felt listened to, understood and respected, which was important for their health and well-being.

It feels like we can socialize, people on the shop floor and people in the office, it's not that strange and everyone kind of knows each other, on equal terms. We're all important for what we do. (Female first-line manager, private organization)

They described that if they had felt they did not belong, they would not have felt well and would not have been able to perform their work.

\subsubsection{Practical assistance}

The managers described that they got support in terms of practical assistance and help both from sources within and outside their workplaces to carry out or complete a certain task. They also mentioned that they collaborated in work tasks and joint projects, mostly with managerial colleagues within the division. Without this practical assistance and collaborations, they thought their work would be much more difficult to perform. 
I'd like to point out that the personnel department gives me very good support. You could say that I have more support from them than I have from my manager. (Female first-line manager, municipal organization)

\subsubsection{Feedback}

Feedback was mentioned as support, and was considered important for two different reasons. Occasionally, the managers received feedback that helped them develop their leadership. This was often received from their subordinates, and sometimes from customers and clients. If this feedback was presented to them at the wrong time or in the wrong forum though, they felt questioned, criticized and stressed.

As a manager, you're obviously more exposed and get feedback whether you want it or not in a very straightforward way and you must be able to take that // Of course it can affect you if you're not mentally prepared for it, then it can make you feel dejected. (Male first-line manager, private organization)

Feedback could also be important for their well-being. The managers described that when they had done something well, they felt appreciated by their superiors, colleagues and subordinates. They described that customers and clients sometimes gave them appreciative feedback, and they felt that they had done a good job.

\subsubsection{Confidence}

Supportive sources within the workplace also gave the managers support indirectly by showing that they had confidence in their managerial abilities. The managers felt that the decisions they made were supported, and that people did not interfere in how the work was carried out.

Both my manager and his manager have made it very clear that they have $100 \%$ faith in what I do. They've explicitly told me that they stand behind me in issues I need help with. So I know that I have a mandate. They don't interfere in the purely operational parts of the job as long as things run smoothly. I use my own discretion, which is nice. (Male first-line manager, private organization)

This was mostly mentioned with regard to the managers' superiors, but some also mentioned the subordinates' confidence. They thought that this discretion contributed to an image of 
being a competent and able manager, because they would be perceived as less reliant on their superiors.

On the other hand, when the managers perceived that others did not have confidence in them, they felt undermined as managers.

I've been given the responsibility to do something and then she [the superior manager] interferes like an infant school teacher and makes corrections in a report that I'm supposed to deliver to the committee. // A little comma in the wrong place, that's something you can live with - but I think it does more damage too. Don’t they even trust me to write these lines? (Male middle manager, municipal organization)

[Insert Table 2 about here]

\subsection{Facilitators and hindrances of social support}

In the managers descriptions, four facilitators or hindrances were discernible that helped or prevented them from seeking and receiving social support: The location of the workplace, formal and informal meetings, vocational courses, and the managerial role.

\subsubsection{The location of the workplace}

Managers’ access to social support from sources within the workplace was facilitated by the location of their workplaces. Those managers whose workplaces were located near their colleagues', superiors' or subordinates' workplaces described how this made it easier for them to find the support they needed when they needed it. They described how they regularly walked over to their colleagues in the offices next door, especially to those who had similar work tasks.

As soon as I get stuck or have a question, I go to one of the others and talk about it, and it feels really nice. I sometimes wonder what it would be like if we didn't have these good relations or if it wasn't so easy, just walking into each other's offices, informing each other or taking advice, it's really good. (Female middle manager, municipal organization) 
The importance of the workplace as a facilitator of social support was particularly evident in those managers whose workplaces were located apart from their colleagues and subordinates. They described how the physical distance made their work much more complicated. They could not have spontaneous contact with their colleagues and subordinates when necessary and communication was slow. They also felt isolated and felt that no one cared about them.

We don't all meet every week, we're not in the same office, and we can't meet in the corridor. We have a lot of telephone meetings but I wish I had more direct contact face-to-face with my staff. (Male middle manager, private organization)

Having a workplace near others were however not entirely positive as this also meant getting disturbed more often. People came for advice, had questions and some only wanted to chat.

\subsubsection{Formal and informal meetings}

The managers also mentioned that meetings helped them make contact with people. In particular, managers in the private organization mentioned a meeting that was held every morning, which most of the employees in the division attended. At such meetings, the managers could easily find the person and the support they needed.

We have our morning meeting every morning where you meet practically all functions anyway, not always the same people, although some of them are always the same // If you have something you'd like to discuss with someone, you may find the person at these morning meetings. (Male middle manager, private organization)

Informal group meetings were described by managers in both organizations, particularly in relation to support from sources outside the workplace. These meetings were gatherings they had created as supportive forums for themselves, and different supportive functions of those groups were emphasized. Some meetings provided support for their work, others for leadership and still others for health. In the private organization these groups mostly comprised people from within the organization, whereas in the municipal organization they included people from outside the organization as well. 
So there are some managers who've met regularly and you can talk about things that are difficult and hard to deal with, and get support from each other. // I mean, there’s nothing to stop me. I can also get something back there. I mean, test ideas and so on. You can describe a difficult situation and maybe make it up a bit. And it's an open atmosphere where you can sort of find support. (Male middle manager, municipal organization)

Although meetings provided opportunities to ask for support, many thought they already went to too many unnecessary meetings that did not give them anything. They felt they would rather have spent that time on their work and daily leadership instead.

The informal group meetings could also complicate the managers' work situation, because of the time spent away from their work. Because these meetings were voluntary, the managers could not be sure that the person they wanted support from would be at the meeting.

\subsubsection{Vocational courses}

Managers’ access to social support, particularly from sources outside the workplace, was facilitated by vocational courses. In both organizations the managers mentioned that they could attend vocational courses when they asked for it (such as management or leadership development programmes). At these courses, they got information and had discussions with teachers and course participants. These courses were perceived as a platform to get to know other managers and expand their network for future support. In the municipal organization, managers were sent to courses held outside the organization, the courses in the private organization were mostly held within the organization and the contacts were managerial colleagues in other parts and divisions of the organization.

Well, I suppose the main advantage was that you also got access to a network as well. We became a very close-knit group. You feel that you can talk in confidence with these people because you know it won't go any further. Because it's sort of, I mean it was all based on us creating our own forum, and I must say that we still get a lot out of it even today, you have people you can air your ideas and thoughts and problems with. (Male first-line manager, private organization) 
Attending a vocational course was however demanding and could complicate the managers' work situation. They had to leave the workplace, and their absence made them feel stressed. They described that while they were away the workload would increase and they would be less accessible to their subordinates. For this reason, they sometimes refrained from participating in such courses.

\subsubsection{Managerial role}

In the managers' descriptions, it was clear that the managerial role sometimes made it difficult for them to seek support, especially from supportive sources within the workplace. Several managers said they felt lonely in their managerial role because of this.

Yes, but I mean you feel quite alone. Of course you can talk to your bosses, or your colleagues in the management group, but at the end of the day, you're actually quite alone with your problems, because of course they have their own problems. (Female first-line manager, private organization)

They believed they could not turn to their subordinates because they could not be too involved or share too much with them. The managers could not turn to their colleagues because they often competed for the same financial resources. They could not turn to their superiors because they felt that as managers they were expected to, or felt it was their responsibility to, know how to handle things.

Many managers described the necessity of performing well and maintaining an image of being a competent and performing manager. Some said that they only asked for support when it was obvious that they would not be able to perform the task themselves, others said that they did not necessarily seek support at all even when they might have needed it.

But the important thing is of course that if we're not going to be able to do something, it's important to say so in good time, and I mean it's always difficult to eat humble pie - you tend to keep going until it may be a bit too late. I suppose that you think right up to the very last that you're going to manage it. (Male middle manager, private organization)

They also said that the expectation of the managerial role was to provide support, not receive it. It was therefore their responsibility as a manager to create a functioning support system 
that did not rely on the support of sources within the workplace. Because they thought it would be problematic to ask for support regarding certain issues from the people they worked closely with, they turned to sources outside their workplace instead.

I have a network in [municipality 1] and a couple of colleagues in [municipality 2], and not just colleagues but also a [manager in a different field] whom I talk to. We don’t meet during working hours, but we see each other from time to time and talk. That's also important for me, I can’t confide in the [employees], because I'm their manager. And I can't discuss with anyone else here either. When it comes to me and my views on different aspects of the work, I have to raise them elsewhere. But I have to say that I use these people more than I use the people I know within the municipality. (Female first-line manager, municipal organization)

\section{Discussion}

The purpose of this study was to increase knowledge about managers' perception of workrelated social support and facilitators and hindrances that helps respectively inhibits managers from seeking social support at work. The results show that supportive sources within and outside the workplace differed in the types of support they provided the managers with. Support that directly helped the managers to perform their work tasks was sought mostly from sources within the workplace. Support that helped them develop their leadership or their health was mostly sought from sources that were outside their workplace. The results also show that managers' social support seeking were facilitated by access to different arenas, where support from sources within or outside the workplace could be found. However, these arenas could also be hindrances to support seeking, as they were demanding and challenging to attend. A further hindrance was the managerial role and maintaining an image of being competent. These hindrances could therefore result in managers refraining from asking for support.

\subsection{Work-related support is sought from sources within the workplace}


The managers deliberatively sought work-related support from persons that had relevant information and help to give [4]. This frequent and insightful support was important to the managers: Information and help contributed to their work performance and the support gave them discretion and ability to do their work. This in turn allowed the managers to build or maintain their managerial image of being competent, which was important to maintain the confidence of the closest organization [e.g. 53-59].

The exchange of work-related support was facilitated by the arrangement of the organizational work space [44-46]. Geographic proximity, in terms of the location of the managers' offices in relation to others, as well as the organization of meetings, in terms of frequency and involvement of others, formed social arenas where managers could gain access to relevant supportive sources. When the managers had difficulties gaining access to these arenas, relevant support decreased, e.g. essential information, and they had difficulties to perform their work and they felt stressed [74-75].

\subsection{Sensitive and personal support is sought from sources outside the workplace}

The managers expressed concern that asking for certain types of support which was sensitive and personal could potentially harm the confidence of the people they were dependent on, thus jeopardizing their image as managers. When the managers needed support that involved ventilating their own stress, or discussing leadership and difficult personnel issues, they turned to people who were outside their workplace, those who they did not work closely with, and whose confidence they were not dependent on. To get these types of support, the managers had to openly describe a perceived problem, and this made them vulnerable, e.g. to criticism. This openness therefore required mutual trust $[67,76]$ that the information would not be passed on to people they worked with, and whose confidence they depended on and wanted to preserve. These sources were often old colleagues now working elsewhere, or people they had met at vocational courses, or informal gatherings with colleagues they 
trusted. By turning to sources outside the workplace, in different arenas than sources within the workplace, the managers could themselves control what information they revealed, and thereby not jeopardize their image and the confidence of the people they worked with.

\subsection{Sources within and outside the workplace are deliberately separated}

The managers solved the question of potentially jeopardized image and confidence by distinguishing between different sources, based on what supportive function they had and in which arenas they were found. Sources within the workplace were used to build or maintain their perceived image. Sources outside the workplace were used to gain support for sensitive and personal issues and thereby avoid jeopardizing their image and the confidence of sources within the workplace. By distinguishing in this way, they gained personal distance from their managerial responsibilities [51] and maintained the impression of being competent [58]. They kept the confidence of sources within the workplace and kept the sources outside the workplace remote. The practice of such political skills, or impression management, has been shown to be an important part of keeping the confidence of subordinates and thereby being able to perform one’s work [53-59]. Sometimes there were exceptions to this pattern of distinguishing between supportive sources and arenas; for example, when they received support they had not asked for. Receiving feedback from sources within the workplace could make the managers feel stressed and criticized if it was provided in the wrong forum, i.e. in front of people whose confidence the manager wanted to preserve. Such imposed support may question the managers’ competence, which may result in stress reactions [65-67].

\subsection{Sensitive support requires control over information}

All the managers in this study considered support important, but it was up to individual managers to create their own support network, especially with reference to the more sensitive types of support. Thus, they did not want the organization to be involved in the creation of their support network [cf. 45], possibly because of the risk of being questioned as a manager. 
A support network created by and under the organization's control most likely includes people the managers are dependent on, and whose confidence they want to preserve. In this kind of arena, the managers cannot control what information they reveal or the people they choose to share that information with. Thus, the mutual trust that is necessary for the exchange of sensitive support is inhibited by the worry of losing face and being criticized. The situation may also be perceived as artificial and the support as imposed, which has negative consequences [65]. Arenas that are not created by the organization, and therefore not under its control, become a safe space [76-78] because the exchange of support is under the control of the individual manager.

Vocational courses were described in this study as one such safe space for the exchange of social support. Previous research has shown that managerial courses facilitates the acquisition of social support [31,46-48]. Management programmes have also been suggested to be safe spaces, separated from managers' daily work, that allow them to build or strengthen their identity as managers, because they are reluctant to entrust or allow their workplace to be a part of that identity work [48,77-78]. In this study vocational courses were an important arena for access to social support, as they gave the managers knowledge and information and facilitated valuable discussions. At these courses the managers also made contact with course participants who were often managers in other organizations, and who could potentially be used for future support. The course was therefore an arena for support because it was a safe space detached from their daily work, and the managers dared to open up and be vulnerable [77-78].

\subsection{Support is avoided if it is too costly}

Participation in arenas that gave the managers access to social support, and safe spaces in particular, demanded a temporal investment, and a spatial move away from the workplace. In the same way as the managers established contacts with potentially supportive sources, they 
also became a supportive source for others; thus there was a risk of having to reciprocate support. The managers' work conditions could therefore inhibit their support seeking [5]. They refrained from seeking support if they did not have the time, if their workload did not allow them to be absent from their work or act as a supportive source to someone else. The managers had to choose and prioritize regarding which arenas they should participate in, and when they should do so, based on their work conditions, the support they needed and from whom. Thus, they sometimes waited to seek support or did not seek it at all. The facilitators at work for managers' support seeking, could therefore also be hindrances to their support seeking. In their efforts to preserve the confidence of the people their work depended on, and maintain the image of being competent and able, the managers risked having this image questioned by these very same people because they did not ask for support when they needed it [79-80].

\subsection{Few organizational differences}

This study showed great similarities between managers, regardless of organizational affiliation. Previous research has often focused on differences between public and private organizations [e.g. 81]. These differences have often been assumed to depend on differences in goals, purpose and structure. In this study, the various types of support were described by managers in both organizations, suggesting that they are important resources for practicing leadership in a managerial position. In their descriptions, a division between sources within and outside the workplace were also discernible, suggesting that fear of getting their competence and ability questioned is an issue for managers regardless of affiliation. The organizations differed regarding who the sources outside the workplace were, which seem to be related to how the vocational courses and meetings were organized.

\subsection{Limitations and future research}


The qualitative design of this study allowed a deeper understanding of managers' social support and aspects influencing their seeking of support at work. A limitation of this study may be the lack of a developed gender perspective. We chose to focus on differences and similarities between the two organizations. Previous research has shown that male and female managers’ organizational networks differ [e.g. 82-83], and future research could investigate what consequences such possible differences might have for male and female managers’ social support and support seeking.

A further area for future research might be to investigate managers' social support from a subordinate perspective. Previous research has shown that managers who are highly politically skilled and who use impression management are considered better managers [e.g. 56]. Previous research has also shown that managers are considered more trustworthy if they are open [e.g. 84]. But how open should they be, and about what? Thus, how much can and should a manager share with subordinates, in terms of both content and amount, without losing the subordinates' confidence? Such knowledge may be used to create conditions that encourage support-seeking behaviours and reduce unwarranted fear of being considered incompetent or unable to handle a managerial position.

\section{Contributions}

This study makes several theoretical contributions. House [7] suggested that in order to gain a deeper understanding of social support, investigations should concern 'who gives what to whom regarding which problems’ (p. 22). Our research was inspired by his suggestion, but we also tried to answer research calls for a contextualization of social support [e.g. 1-6]. We did this by also investigating the facilitators and hindrances at work for managers' support seeking. Our study shows how closely type of support, source of support, and arenas for support are connected in the social support process, and how important it is that they match, 
for the social support to be experienced as positive. The optimal matching hypothesis $[4,43]$ suggests that type of support and source of support must match in order for support to be effective. Our study expands this hypothesis and suggests that the arena where the exchange of support takes place is equally important.

This study contributes to the understanding of social support and of managers' social support system by showing that, in order to preserve their image of being competent and able, managers seek support from different sources, in various distinct arenas, based on the types of support these sources provide. We thus extend previous research which shows that different sources at different places provide different types of support [4,42], by providing an explanation as to why this is so. More specifically, we highlight the importance of individual choice. Social support is often treated as something a person either owns or not. This study, on the other hand, generally shows that individuals are active agents in creating their social support network. We show how important managers’ perception of the managerial role and maintaining an image of being competent and able is for shaping their social support network, i.e. who and where they ask for certain types of support. We also show how the demands of the supportive arenas and the need to reciprocate can be a hindrance as this may increase stress and strain, which is important for whether or not managers seek support. Thus, our findings indicate that the esteem threat hypothesis and the inequity hypothesis [6,65-67] have different relevance in the social support-seeking process. Using only one of these hypotheses as a starting point is not sufficient, as it will result in an inability to capture the processual nature of social support.

In the literature concerning social support, the discussion is often quite categorical regarding whether social support is beneficial or not. This study rather shows that social support can be beneficial, but it depends on who, where and why it is provided. Emotional support that concerns ventilating managers’ personal views and stress is negative if it occurs 
with the wrong sources and in the wrong forums. What may be intended as support from the sources perspective may be interpreted as a threat to the managers' image and invoke negative reactions.

Our study also contributes methodologically to previous social support literature because we used a qualitative approach, where most studies have been quantitative. This procedure allowed the different types of support to emerge from the data, rather than being labelled in predefined categories. Research on social support usually distinguishes between four different types of support [6,8], in accordance with House [7]. Our findings contribute with a more nuanced picture of House’s [7] typologies and why they are important for managers. Our approach allowed us to identify subtypes and patterns, which we would not have been able to do if we had only used House's [7] broader types. Instead of 'information' we could see what particular type of information was being exchanged etc. In our study, a distinction was made between information possessed by the source and shared to the manager, and discussions that to a large extent are concerned with creating new knowledge together. In House’s [7] conceptualization, discussion is viewed as advice, and is therefore considered a form of information. However, by making this differentiation we could see that the content of the discussions and information differed somewhat between sources and arenas. Furthermore, House’s [7] typology does not recognize other people showing confidence as a type of support. This may be because previous research has not focused on social support in managers, and the confidence of others may be specific, or at least more important, for managers. Nevertheless, our results suggest that confidence is an important type of support that managers try to maintain by differentiating between different supportive sources. Confidence in the manager has been emphasized in other types of research as important for managers' leadership and performance [e.g. 85]. It has also been described as an important part of building and maintaining managers’ authority [e.g. 53-59]. Since House’s [7] typology 
does not include confidence as a type of support, previous research has overlooked one of the reasons as to why managers' seek different types of support from different sources. Support from sources within the workplace contributes to building managers' image, and sources outside the workplace are used to maintain their image and the confidence of sources within the workplace. Our findings therefore suggest that confidence should be added as a type of social support, as it enhances our understanding of the social support-seeking process in managers.

This study also makes practical contributions. The distinction that managers make between different sources of support, to avoid jeopardizing their image, has practical relevance for how they accomplish their assignments, most obviously when they do not ask for support despite the fact that they need it. These results emphasize the importance of creating an organizational culture where managers dare to ask for support without fear of losing face, being criticized or being judged as incompetent [77,86-88]. Organizations should also encourage managers’ networking outside their organization, as such networks are important for personal development, well-being and for generating ideas and innovation [35,47]. The results further suggest that it is important for organizations to create forums and arenas for support, without trying to control the arena or impose the support. This could be done for instance by creating discussion groups that do not encompass immediate supervisors. A second strategy would be to encourage participation in vocational courses.

This study shows that vocational courses are considered safe spaces in which managers dare to open up and ask for support which they otherwise would have considered too sensitive and personal $[77,86-88]$. Therefore the results also have practical relevance for organizers of vocational management courses. Awareness of the dilemma that managers face when asking for support might be used as a learning opportunity within the course. They also need to be aware that their course might fulfil other purposes for the participants than the ones intended. 
Thus, on vocational management courses the supportive aspects should be given greater emphasis, and opportunities for networking should be facilitated [77].

\section{Conclusions}

This study shows that social support is important for practicing leadership and handling a managerial position, serving several functions for managers concerning their work, leadership and personal well-being. The benefits of social support are however contingent on who provides the support and where it is provided. Different supportive sources are distinguished based on what supportive function they have and in which arenas they are found. This is done to preserve the confidence of the closest organization and to maintain the image of being a competent and performing manager. Attending arenas for support is however demanding and managers may refrain from seeking support if it is considered too costly, thereby jeopardizing their managerial image. 


\section{References}

[1] Beggs JJ, Haines VA, Hurlbert JS. Situational contingencies surrounding the receipt of informal support. Social Forces. 1996; 75: 201-222.

[2] House JS, Landis KR, Umberson D. Social relationships and health. Science. 1988; 241: $540-554$.

[3] House JS, Umberson D, Landis KR. Structures and processes of social support. Annual Review of Sociology. 1988; 14: 293-318.

[4] Lindorff M. Determinants of received social support: Who gives what to managers? Journal of Social and Personal Relationships. 2005; 22: 323-337.

[5] Sundin L, Bildt C, Lisspers J, Hochwälder J, Setterlind S. Organisational factors, individual characteristics and social support. What determines the level of social support? Work. 2006; 27: 45-55.

[6] Nurullah AS. Received and provided social support: A review of current evidence and future directions. American Journal of Health Studies. 2012; 27: 173-188.

[7] House JS. Work stress and social support. Reading, MA: Addison-Wesley; 1981.

[8] Langford CPH, Bowsher J, Maloney JP, Lillis PP. Social support: A conceptual analysis. Journal of Advanced Nursing. 1997; 25: 95-100.

[9] Shumaker SA, Bronwell A. Toward a theory of social support: Closing conceptual gaps. Journal of Social Issues. 1984; 40: 11-33.

[10] Blau PM. Exchange and power in social life. New York: John Wiley; 1964.

[11] Gouldner AW. The norm of reciprocity: A preliminary statement. American Sociological Review. 1960; 25: 161-178.

[12] Munduteguy, C. Exploring the nature and consequences of a fragmented activity: The example of foremen managing operations in an inland port. Work. 2012; 41: 6039-6046. 
[13] Styhre A, Josephson P-E. Revisiting site manager work: Stuck in the middle? Construction Management and Economics. 2006; 24: 521-528.

[14] Sundkvist Y, Zingmark K. Leading from intermediary positions. First-line administrators' experiences of their occupational role and situation. Scandinavian Journal of Occupational Therapy. 2003; 10: 40-46.

[15] Udod SA, Care WD. 'Walking a tight rope’: An investigation of nurse managers’ role stressors and coping experiences. Journal of Research in Nursing. 2013; 18: 67-79. [16] Udod S, Cummings GG, Care WD, Jenkins M. Role stressors and coping strategies among nurse managers. Leadership in Health Services. 2017; 30: 29-43.

[17] Hales C. Rooted in supervision, branching into management: Continuity and change in the role of first-line manager. Journal of Management Studies. 2005; 42: 471-506. [18] Tengblad S. Is there a 'new managerial work'? A comparison with Henry Mintzberg's classic study 30 years later. Journal of Management Studies. 2006; 43: 1437-1461. [19] Peterson MF, Smith PB, Akande A, Ayestaran S, Bochner S, Callan V, et al. Role conflict, ambiguity, and overload. A 21-nation study. Academy of Management Journal. 1995; 38: 429-452.

[20] Van Bogaert P, Adriaenssens, J, Dilles T, Martens D, Van Rompaey B, Timmermans O. Impact of role-, job- and organizational characteristics on Nursing Unit Managers’ work related stress and well-being. Journal of Advanced Nursing. 2014; 70: 2622-2633.

[21] Wong, S-S, DeSanctis G, Staudenmayer N. The relationship between task interdependency and role stress: A revisit of the job demands - control model. Journal of Management Studies. 2007; 44: 284-303.

[22] Dhar RL. Employees’ perception of organizational support: A qualitative investigation in the Indian information technology (IT) industry. Work. 2012; 43: 211-222. 
[23] Lindholm M. Working conditions, psychosocial resources and work stress in nurses and physicians in chief managers’ positions. Journal of Nursing Management. 2006; 14: 300-309. [24] Weiss M. Effects of work stress and social support on information systems managers. MIS Quarterly. 1983; 7: 29-43.

[25] Etzion D. Moderating effect of social support on the stress - burnout relationship. Journal of Applied Psychology. 1984; 69: 615-622.

[26] Lindholm M, Dejin-Karlsson E, Östergren P-O, Udén G. Nurse managers’ professional networks, psychosocial resources and self-rated health. Journal of Advanced Nursing. 2003; 42: $506-515$.

[27] Bernin P, Theorell T, Sandberg CG. Biological correlates of social support and pressure at work in managers. Integrative Physiology and Behavioral Science. 2001; 36: 121-136.

[28] Stoetzer U, Bergman P, Åborg C, Johansson G, Ahlberg G, Parmsund M, Svartengren M. Organizational factors related to low levels of sickness absence in a representative set of Swedish companies. Work. 2014; 47: 193-205.

[29] Chiaburu DS, Van Dam K, Hutchins HM. Social support in the workplace and training transfer: A longitudinal analysis. International Journal of Selection and Assessment. 2010; 18: $187-200$.

[30] Gilpin-Jackson Y, Bushe GR. Leadership development training transfer: A case study of post-training determinants. Journal of Management Development. 2007; 26: 980-1004.

[31] Lee H, Spiers JA, Yurtseven O, Cummings GG, Sharlow J, Bhatti A, Germann P. Impact of leadership development on emotional health in healthcare managers. Journal of Nursing Management. 2010; 18: 1027-1039.

[32] Tracey JB, Tannenbaum SI, Kavanagh MJ. Applying trained skills on the job: The importance of the work environment. Journal of Applied Psychology. 1995; 80: 239-252. 
[33] Ouweneel APE, Taris TW, van Zolingen SJ, Schreurs PJG. How task characteristics and social support relate to managerial learning: Empirical evidence from Dutch home care. Journal of Psychology. 2009; 143: 28-44.

[34] Turner M, Mariani A. Managing the work-family interface: Experience of construction managers. International Journal of Managing Projects in Business. 2016; 9: 243-258.

[35] Cullen-Lester KL, Gerbasi, A, White S. The promise and peril of workplace connections: Insights for leaders about workplace networks and well-being. Research in Occupational Stress and Well Being. 2016; 14: 61-90.

[36] Laschinger HKS, Purdy N, Cho J, Almost J. Antecedents and consequences of nurse managers’ perceptions of organizational support. Nursing Economics. 2006; 24: 20-29. [37] Kawada T, Otsuka T. Relationship between job stress, occupational position and job satisfaction using a brief job stress questionnaire (BJSQ). Work. 2011; 40: 393-399. [38] Lundqvist D, Reineholm C, Gustavsson M, Ekberg K. Investigating work conditions and burnout in three hierarchical levels. Journal of Occupational and Environmental Medicine. 2013; 55: 1157-1163.

[39] Skakon, J, Kristensen, TS, Christensen KB, Lund T, Labriola M. Do managers experience more stress than employees? Results from the Intervention Project on Absence and Well-being (IPAW) study among Danish managers and their employees. Work. 2011; 38: 103-109.

[40] Vinberg S, Romild U, Landstad BJ. Prevention and rehabilitation in Swedish public sector workplaces: Effects on co-workers' and leaders’ health and psychosocial working conditions. Work. 2015; 52: 891-900.

[41] Lingard H, Francis V. Does a supportive work environment moderate the relationship between work-family conflict and burnout among construction professionals? Construction Management and Economics. 2006; 24: 185-196. 
[42] Love PED, Edwards DJ. Taking the pulse of UK construction project managers' health. Influence of job demands, job control and social support on psychological wellbeing. Engineering, Construction and Architectural Management. 2005; 12: 88-101.

[43] Cohen S, Wills TA. Stress, social support, and the buffering hypothesis. Psychological Bulletin. 1985; 98: 310-357.

[44] Fleming R, Baum A, Singer JE. Social support and the physical environment. In: Cohen S, Syme SL, editors. Social support and health. Orlando, FL: Academic Press; 1985: 327345.

[45] Dellve L, Wikström E. Managing complex workplace stress in health care organizations: Leaders’ perceived legitimacy conflicts. Journal of Nursing Management. 2009; 17: 931-941. [46] Larsson R, Åkerlind I, Sandmark H. Managing workplace health promotion in municipal organizations: The perspective of senior managers. Work. 2016; 53: 485-498.

[47] Burt RS, Hogart RM, Michaud C. The social capital of French and American managers. Organization Science. 2000; 11: 123-147.

[48] Moorosi P. Constructing a leader’s identity through a leadership development programme: An intersectional analysis. Educational Management Administration \& Leadership. 2014; 42: 792-807.

[49] Arora R, Rangnekar S. Workplace mentoring and career resilience: An empirical test. The Psychologist-Manager Journal. 2014; 17: 205-220.

[50] Scandura TA, Viator RE. Mentoring in public accounting firms: An analysis of mentorprotégé relationships, mentorship functions, and protégé turnover intentions. Accounting, Organizations and Society. 1994; 19: 717-734.

[51] Skagert K, Dellve L, Eklöf M, Pousette A, Ahlborg Jr G. Leaders’ strategies for dealing with own and their subordinates' stress in public human service organisations. Applied Ergonomics. 2008; 39: 803-811. 
[52] Veach TL, Rahe RH, Tolles RL, Newhall LM. Effectiveness of an intensive stress intervention workshop for senior managers. Stress and Health. 2003; 19: 257-264.

[53] Brickle G, Schneider PB, Liu Y, Ferris, GR. A predictive investigation of reputation as mediator of the political-skill/career-success relationship. Journal of Applied Social Psychology. 2011; 41: 3026-3048.

[54] Ellen BP III, Ferris GR, Buckley MR. Leader political support: Reconsidering leader political behavior. The Leadership Quarterly. 2013; 24: 842-857.

[55] Harris KJ, Kacmar KM, Zivnuska S, Shaw JD. The impact of political skill on impression management effectiveness. Journal of Applied Psychology. 2007; 92: 278-285. [56] Kacmar KM, Wayne SJ, Wright PM. Subordinate reactions to the use of impression management tactics and feedback by the supervisor. Journal of Managerial Issues. 2009; 21: $498-517$.

[57] Mecl J, Wefald AJ, van Ittersum KW. Transformational leader attributes: Interpersonal skills, engagement, and well-being. Leadership \& Organization Development Journal. 2016; 37: 635-657.

[58] Pfeffer J. The ambiguity of leadership. Academy of Management Review. 1977; 2: 104112.

[59] Snell SJ, Tonidandel S, Braddy PW, Fleenor JW. The relative importance of political skill dimensions for predicting managerial effectiveness. European Journal of Work and Organizational Psychology. 2013; 915-929.

[60] Ashford SJ, Rothbard NP, Piderit SK, Dutton JE. Out on a limb: The role of context and impression management in selling gender-equity issues. Administrative Science Quarterly. 1998; 43: 23-57. 
[61] Dutton JE, Ashford SJ, O’Neill RM, Hayes E, Wierba EE. Reading the wind: How middle managers assess the context for selling issues to top managers. Strategic Management Journal. 1997; 18: 407-423.

[62] Piderit SK, Ashford SJ. Breaking silence: Tactical choices women managers make in speaking up about gender-equity issues. Journal of Management Studies. 2003; 40: 14771502.

[63] Kaufmann GM, Beehr TA. Interactions between job stressors and social support: Some counterintuitive results. Journal of Applied Psychology. 1986; 71: 522-526.

[64] Lindorff M. Is it better to perceive than receive? Social support, stress and strain for managers. Psychology, Health \& Medicine. 2000; 5: 271-286.

[65] Deelstra J T, Peeters MCW, Schaufeli WB, Stroebe W, Zijlstra FRH, van Doornen LP. Receiving instrumental support at work: When help is not welcome. Journal of Applied Psychology. 2003; 88: 324-331.

[66] Dunbar M, Ford G, Hunt K. Why is the receipt of social support associated with increased psychological distress? An examination of three hypotheses. Psychology and Health. 1998; 13: 527-544.

[67] Fisher JD, Nadler A, Whitcher-Alagna S. Recipient reactions to aid. Psychological Bulletin. 1982; 91: 27-54.

[68] Kvale S. Interviews: An introduction to qualitative research interviewing. Thousand Oaks, CA: Sage; 1996.

[69] Liker JK. The Toyota way: 14 management principles from the world’s greatest manufacturer. New York: McGraw-Hill; 2004.

[70] Elo S, Kyngäs H. The qualitative content analysis process. Journal of Advanced Nursing. 2008; 62: 107-115. 
[71] Hsieh H-F, Shannon SE. Three approaches to qualitative content analysis. Qualitative Health Research. 2005; 15: 1277-1288.

[72] Schilling J. On the pragmatics of qualitative assessment. Designing the process for content analysis. European Journal of Psychological Assessment. 2006; 22: 28-37.

[73] Patton MQ. Qualitative Research \& Evaluation Methods. 4th ed. Thousand Oaks, CA: Sage; 2015.

[74] Lindorff M. Are they lonely at the top? Social relationships and social support among Australian managers. Work and Stress. 2001; 15: 274-282.

[75] Mohr G, Wolfram H-J. Stress among managers: The importance of dynamic tasks, predictability, and social support in unpredictable times. Journal of Occupational Health Psychology. 2010; 15: 167-179.

[76] Kahn WA. Holding environments at work. Journal of Applied Behavioral Science. 2001; 37: $260-279$.

[77] Hay A. 'I don’t know what I am doing!’: Surfacing struggles of managerial identity work. Management Learning. 2014: 45; 509-524.

[78] Petriglieri G, Petriglieri JL. Identity workspaces: The case of business schools. Academy of Management Learning \& Education. 2010; 9: 44-60.

[79] Ashforth BE, Gibbs BW. The double-edge of organizational legitimation. Organization Science. 1990; 1: 177-194.

[80] Falkenberg A, Nyfjäll M, Vingård, E. Social support at work and leisure time and its association with self-rated health and sickness absence. Work. 2012; 43: 469-474. [81] Hales C. Why do managers do what they do? Reconciling evidence and theory in accounts of managerial work. British Journal of Management. 1999; 10: 335-350.

[82] Ibarra H. Paving an alternative route: Gender differences in managerial networks. Social Psychology Quarterly. 1997; 60: 91-102. 
[83] Gustavsson M, Fogelberg Eriksson A. Gendered learning environments in managerial work. Studies in the Education of Adults. 2010; 42: 141-155.

[84] Byrne Z, Pitts V, Chiaburu D, Steiner Z. Managerial trustworthiness and social exchange with the organization. Journal of Managerial Psychology. 2011; 26: 108-122.

[85] Dirks KT, Ferrin DL. Trust in leadership: Meta-analytic findings and implications for research and practice. Journal of Applied Psychology. 2002; 87: 611-628.

[86] Ellström P-E. Informal learning at work: Conditions, processes and logics. In: Alloch MM, Cairns L, Evans K, O'Connor BN, editors. The Sage Handbook of Workplace Learning. Thousand Oaks, CA: Sage; 2010: 105-119.

[87] Schein EH. The Corporate Culture Survival Guide. San Francisco: Jossey-Bass; 2009. [88] Schein EH. Organizational Culture and Leadership. 4rd ed. San Francisco: Jossey-Bass; 2010. 
Table 1. Number of Participants (no. men/women), Average Age and Average Years of Managerial Experience within the Organization, Average Span of Control, with regard to Managerial Level and Organizational Affiliation

\begin{tabular}{|c|c|c|c|c|c|c|}
\hline & \multicolumn{3}{|c|}{ Municipal organization } & \multicolumn{3}{|c|}{ Private organization } \\
\hline & $\begin{array}{l}\text { First-line } \\
\text { managers }\end{array}$ & $\begin{array}{l}\text { Middle } \\
\text { managers }\end{array}$ & $\begin{array}{l}\text { Executive } \\
\text { managers }\end{array}$ & $\begin{array}{l}\text { First-line } \\
\text { managers }\end{array}$ & $\begin{array}{l}\text { Middle } \\
\text { managers }\end{array}$ & $\begin{array}{l}\text { Executive } \\
\text { managers }\end{array}$ \\
\hline Number & $0 / 9$ & $6 / 3$ & $0 / 2$ & $9 / 10$ & $11 / 4$ & $7 / 1$ \\
\hline Age & 49 & 53 & 53 & 43 & 41 & 51 \\
\hline Experience & 7 & 11 & 19 & 7 & 7 & 12 \\
\hline $\begin{array}{l}\text { Span of } \\
\text { control }\end{array}$ & 45 & 32 & 7 & 16 & 15 & 6 \\
\hline
\end{tabular}


Table 2. Social Support and House's corresponding Support Typology

\begin{tabular}{|c|c|c|c|c|c|}
\hline \multicolumn{2}{|c|}{ Type of support } & \multirow{2}{*}{ Source of support } & \multicolumn{2}{|c|}{ Importance of support } & \multirow{4}{*}{$\begin{array}{c}\text { Corresponding support in House's } \\
\text { typology }\end{array}$} \\
\hline & - & & - & & \\
\hline \multicolumn{2}{|r|}{ What } & \multirow[t]{2}{*}{ Who } & \multicolumn{2}{|c|}{ Why } & \\
\hline & & & If support is received, it: & If support is withheld, it: & \\
\hline \multirow[t]{4}{*}{ Information } & About work & Sources within the workplace & Helps decision-making & Increases stress & Informational \\
\hline & & & Increases image of competency & Makes work tasks harder & \\
\hline & About facts & Sources outside the workplace & Helps decision-making & - & \\
\hline & & & Increases image of competency & & \\
\hline \multirow[t]{3}{*}{ Discussions } & About work & Sources within the workplace & Helps decision-making & Increases stress & \\
\hline & & & Increases image of competency & Makes work tasks harder & \\
\hline & About leadership & Sources outside the workplace & Helps develop leadership & - & \\
\hline Ventilation & & Sources outside the workplace & Increases well-being & - & Emotional \\
\hline Social & & Sources within the workplace & Increases well-being & Gives a sense of & \\
\hline \multirow[t]{2}{*}{ belonging } & & & & loneliness & \\
\hline & & & & Makes work tasks harder & \\
\hline
\end{tabular}


assistance

Sources outside the workplace

Feedback

About leadership

Sources within the workplace

About

Sources within the workplace

appreciation

Sources outside the workplace

Sources within the workplace
Helps develop leadership

Increases stress (if in the wrong

arena)

Makes work tasks easier

Helps develop leadership

Increases stress (if in the wrong

arena)

well-being

Increases well-being

Increases well-being

Increases image of competency
Reduces image of

competency
Appraisal 